\title{
Design of New Quinazoline Derivative as EGFR (Epidermal Growth Factor Receptor) Inhibitor through Molecular Docking and Dynamics Simulation
}

\author{
Herlina Rasyid ${ }^{1}$, Bambang Purwono ${ }^{2}$, and Harno Dwi Pranowo ${ }^{1,2, *}$ \\ ${ }^{1}$ Austrian-Indonesian Centre (AIC) for Computational Chemistry, Faculty of Mathematics and Natural Sciences, \\ Universitas Gadjah Mada, Sekip Utara, Yogyakarta 55281, Indonesia \\ ${ }^{2}$ Department of Chemistry, Faculty of Mathematics and Natural Sciences, Universitas Gadjah Mada, \\ Sekip Utara, Yogyakarta 55281, Indonesia
}

*Corresponding author:

email: harnodp@ugm.ac.id

Received: June 18, 2020

Accepted: September 16, 2020

DOI: $10.22146 /$ ijc. 57012

\begin{abstract}
Erlotinib, Afatinib, and WZ4002 are quinazoline derivative compounds and classified as first, second, and third-generation EGFR inhibitor. All inhibitors have been given directly to cancer patients for many years but find some resistance. These three compounds are candidates as the lead compound in designing a new inhibitor. This work aims to design a new potential quinazoline derivative as an EGFR inhibitor focused on the molecular docking result of the lead compound. The research method was started in building a pharmacophore model of the lead compound then used to design a new potential inhibitor by employing the AutoDock 4.2 program. Molecular dynamics simulation evaluates the interaction of all complexes using the Amber15 program. There are three new potential compounds (A1, B1, and $C 1)$ whose hydrogen bond interaction in the main catalytic area (Met769 residue). The Molecular Mechanics Generalized Born Surface Area (MM-GBSA) binding energy calculation shows that B1 and C1 compounds have lower binding energies than erlotinib as a positive control, which indicates that B1 and $C 1$ are potential as EGFR inhibitor.
\end{abstract}

Keywords: quinazoline; EGFR; molecular docking; molecular dynamics simulation

\section{- INTRODUCTION}

Epidermal Growth Factor Receptor (EGFR) is a protein receptor that plays an important role in proliferation, angiogenesis, metastasis and inhibits the process of apoptosis in several types of cancer cells [1-2]. Excessive expression of this protein responsible for the growth of cancer cells [3-4]. One of the strategies to inhibit the excessive expression of the EGFR receptor is employing the small molecule tyrosine kinase inhibitors [5].

Quinazoline derivative is the group of compounds that have been widely used as EGFR inhibitor [6], such as erlotinib [7], gefitinib [8], afatinib [9], and WZ4002 [10]. Erlotinib and gefitinib are classified as the first-generation EGFR inhibitor. Both compounds have been given to cancer patients orally and show positive results in inhibiting the growth of cancer cells. However, after giving to patients for two years, resistance was found [11].
Afatinib is a second-generation inhibitor that showed good activity against EGFR T790M, but its activity decreased when given to patients who had previously received treatment with erlotinib and found some side effects such as diarrhea and skin rash [12]. Thirdgeneration inhibitors provide activities around 30 to 100 times better on EGFR T790M mutation. However, this compound also showed resistance in the form of a change in the cysteine amino acid to be serine at position 797 (C797S) [13]. Since many resistances were found to the drug compounds that have been used, then the discovery of new drug candidates is continuously performed. One of the computational methods that can be used to design new drug compounds is molecular docking analysis.

Molecular docking is a method for predicting the orientation and conformation of a molecule when binding to another macromolecule to get a stable 
complex structure [14]. Besides, molecular docking is also used to design a new inhibitor by using some molecules as a lead compound. Traxler et al. [15] employed a molecular docking method to design isoflavone and quinolone derivatives based on the pharmacophore model resulting from docking analysis on four lead compounds. The advantage of molecular docking in designing a new inhibitor does not require a large amount of data or only employ some molecules as the lead compounds. Previous research had designed quinazoline derivative compounds by using quantitative structureactivity relationship (QSAR) analysis in large data compounds [16-18] and studied the stability of hydrogen bond formed through compound and protein [19-22]. However, designing a new EGFR inhibitor using a molecular docking approach of the lead compounds such as erlotinib, afatinib, and WZ4002 has never been done. These lead compounds can be used as guidance in designing new compounds by observing the interaction of each compound in EGFR protein and then obtaining the new compounds with better activity. Thereby, this research focused on designing a new quinazoline derivative compound through the docking result of the lead compounds. The interaction stability of new design compounds is then evaluated through molecular dynamics simulation. The new potential compound will have interaction in the main catalytic area of EGFR protein and stable interaction which can be seen in lower binding energy value.

\section{- COMPUTATIONAL METHODS}

\section{Materials}

The complex of EGFR protein against erlotinib (PDB ID: 1M17) was downloaded from http://www.rcsb.org/structure/1M17, afatinib, and WZ4002 as lead compounds.

\section{Software}

The program were used AutoDock 4.2 with the help of AutoDockTools [23], Gaussian 09 [24], GaussView 5.0, Discovery Studio Visualizer [25], UCSF Chimera 1.8.1 [26], and Amber15 with help of AmberTools16 [27], ChemDraw 15.0, and VMD 1.9.2 [28].

\section{Procedure}

\section{Molecular docking analysis}

There were three compounds used as the lead compound, i.e., erlotinib, afatinib, and WZ4002. These compounds were then prepared to dock by selecting the dock prep menu in Chimera software. The docking procedure was performed by using the AutoDock 4.2 program with the help of AutoDockTools, which started by saving the ligand file as a .pdbqt format. Grid box size was set to be $50 \times 50 \times 50 \AA$ center to ligand with spacing $0.375 \AA$ A. Each docking process was set to produce 10 conformations and then selected the best conformation with the lowest binding energy and correct conformation. A complex of protein and ligand was saved in a .pdb format file and visualized using Discovery Studio Visualizer program. Then, the pharmacophore model complied based on the interaction of the lead compound against EGFR protein to design a new EGFR inhibitor. There were three new compounds resulted ( $\mathrm{A} 1, \mathrm{~B} 1$, and $\mathrm{C} 1$ ), then modeled and optimized using DFT B3LYP/6-31G(d,p) method in Gaussian 09 software. The new compounds were docked into the EGFR protein active with the same grid size and spacing.

\section{Molecular dynamics simulation}

There were three new compounds (A1, B1, and C1) resulted from docking analysis (Fig. 1). These new compounds then evaluated their stability interaction against EGFR protein using the molecular dynamics simulation method. The simulation was proceeded by employing the Amber15 and AmberTools16 software package, applying the ff14SB force field.

Complex protein and ligand charges and other parameters are obtained using the RESP fitting procedure and the general AMBER force field (GAFF) [29]. The system was then solvated with a truncated octahedron box of 50661 water using the TIP3P water model [30] and neutralized by eight of $\mathrm{Na}^{+}$ions as the counterions. The SHAKE algorithm was used to keep water molecules rigid.

Each system then subjected to 1000 steps of steepest descent minimization followed by 4000 steps of 


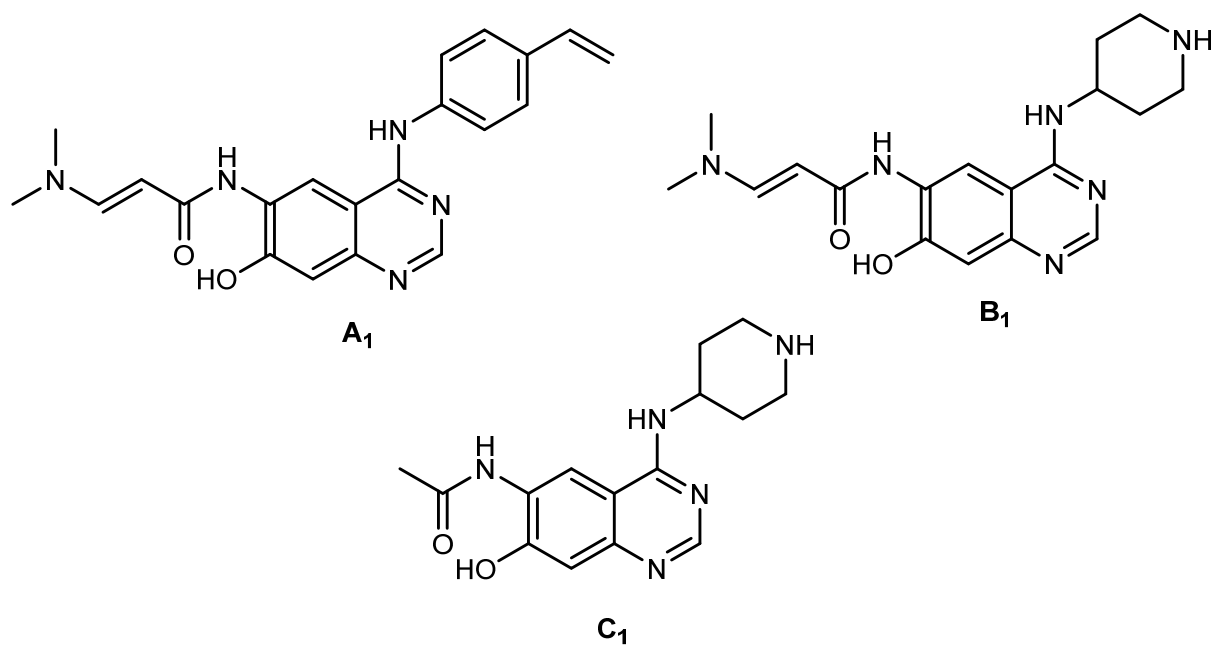

Fig 1. Structures of newly designed compounds A1; B1; and C1

conjugate gradient minimization. Complex protein and ligand were minimized by force constant of $100,50,5$, and 0 (no constraint) $\mathrm{kcal} / \mathrm{mol} \AA^{-2}$. There were 20000 steps in the minimization process.

Following minimization, the heating process was performed. The system was gradually heated from $0 \mathrm{~K}$ until $300 \mathrm{~K}$ and increase every $50 \mathrm{~K}$ in the NVT ensemble for 300 ps. Then continued to density equilibration with time step 2 fs for 300 ps simulation time. The pressure was set at 1 bar applying Berendsen barostat with a relaxation time of 1 ps and temperature was controlled using Langevin thermostat with a collision frequency of $1 \mathrm{ps}^{-1}$ and kept at $300 \mathrm{~K}$. Then the system was relaxed for $500 \mathrm{ps}$ before production data with time step 2 fs during $13 \mathrm{~ns}$ [31-32]. In all simulation steps, Particle Mesh Ewald (PME) [33] was computed with a non-bonded cut off of $12 \AA$. Binding energies were calculated from the MD trajectories using the PBSA module [34] in AMBER15. Every frame that resulted in the production step was utilized to calculate the binding energy of complex protein and ligand. MM-GBSA is typically used to validate earlier molecular docking and MD simulation result. Parameter descriptor of MM-GBSA, such as salt concentration, was set to be $0.1 \mathrm{M}$, and igb was set to be 2 in sander option. Trajectory analysis was done to confirm hydrogen bond distance, Radial Distribution Function (RDF), Root Mean Square Deviation (RMSD), Root Mean Square Fluctuation (RMSF), and binding energy of each system. The stability of the complex is indicated by the low value of binding energy and the highest potential inhibitor from the stable complex protein-ligand.

\section{- RESULTS AND DISCUSSION}

\section{Design of Inhibitors}

There are three compounds used as a lead compound in this work to design new EGFR inhibitors, which is erlotinib, afatinib, and WZ4002. These compounds have been proven as the first, second, and third generation of EGFR inhibitors [35]. The docking analysis from all the compounds is used to build a pharmacophore model for the EGFR inhibitors. Fig. 2 shows the $2 \mathrm{D}$ and $3 \mathrm{D}$ visualization of docking results from the lead compounds. $2 \mathrm{D}$ visualization displays that the lead compounds have a hydrogen bond with Met769 or Met793 residue and the additional bond with Cys797 residue for afatinib compound.

Some interactions were identified, such as van der Waals interactions, salt bridge, and pi- sigma stacking. $3 \mathrm{D}$ visualization of docking results present that all the compounds have fulfilled the cavity of protein EGFR. Using these docking results, potential inhibitors could be obtained with the following conditions: There is a hydrogen bond to the main catalytic residue that is Met769 or Met793, as well as an additional hydrogen bond to the Cys797 residue. This interaction is obtained from docking analysis of afatinib to the EGFR protein; 
(a1)

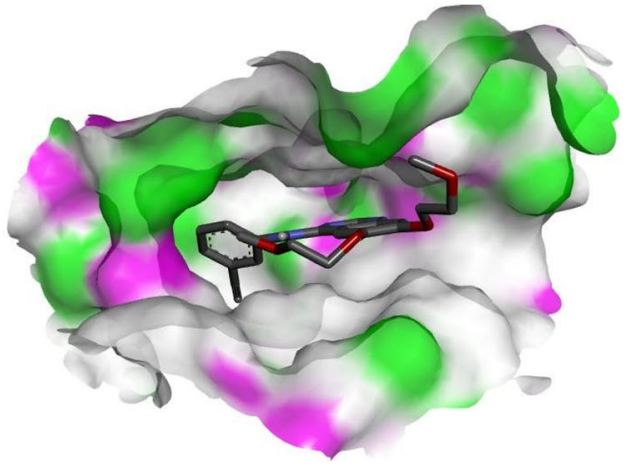

(b1)

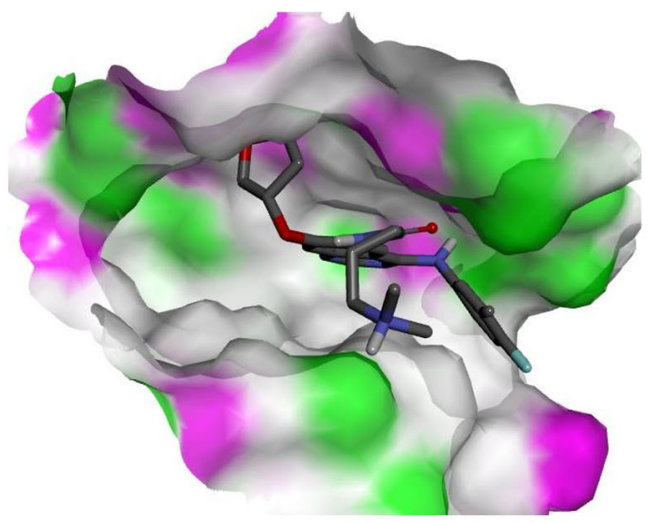

(c1)

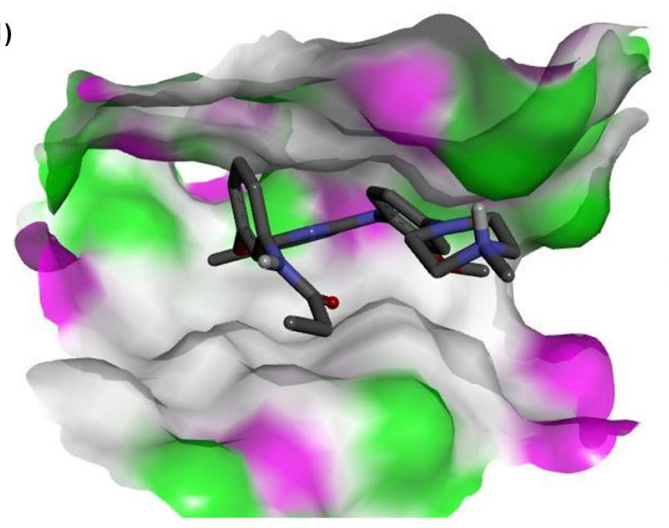

(a2)

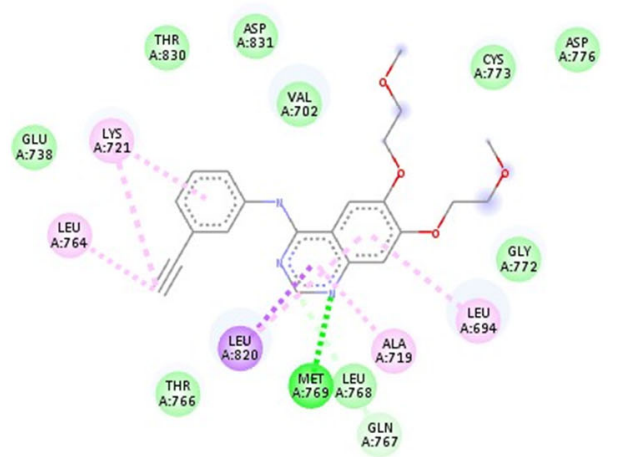

(b2)

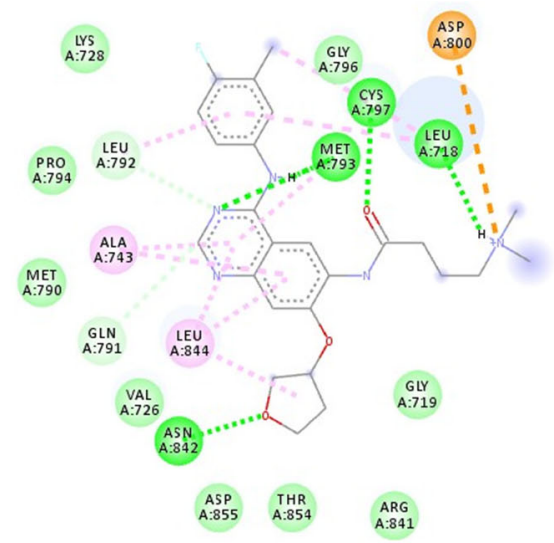

(c2)

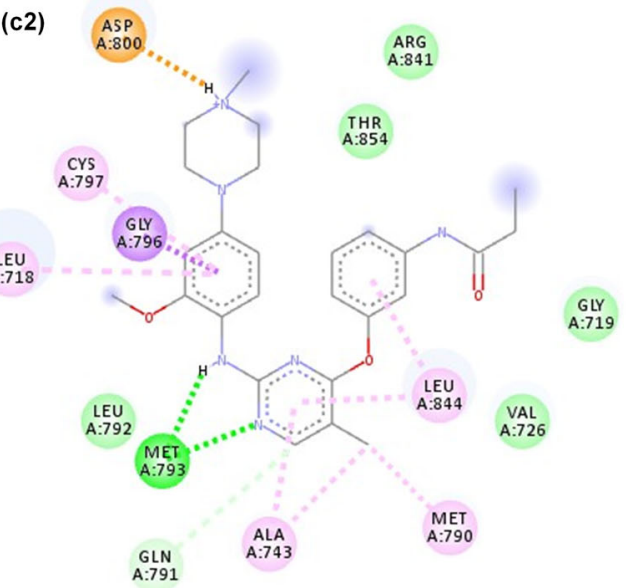

Fig 2. 3D and 2D interactions of (a1) and (a2) erlotinib, (b1) and (b2) afatinib, and also (c1) and (c2) WZ4002 against EGFR protein. Type of interactions: van der Waals, salt bridge, conventional hydrogen bond, carbon hydrogen bond, pi-sigma, and pi-alkyl

there is a $-\mathrm{NH}$ linker group and substitute with small groups to avoid steric obstruction. That linker belongs to all lead compounds that influence the accuracy of the lead compound conformations; there are functional groups that can form hydrophobic interactions. All lead compounds have hydrophobic interactions with some EGFR protein residues, but it should be noted that this interaction should be formed in the hydrophobic region of EGFR protein. All these requirements have been in line with previous research $[13,15,35-39]$. 
The docking analysis result of the new compounds is shown in Fig. 3. All new compounds present a hydrogen bond in the main catalytic area, Met769 residue. This hydrogen bond has an important role in the inhibition mechanism of the EGFR inhibitor. An additional hydrogen bond in the Cys773 residue suppresses the survival of tumor growth in EGFR and HER2 mutants [12].

(a1)

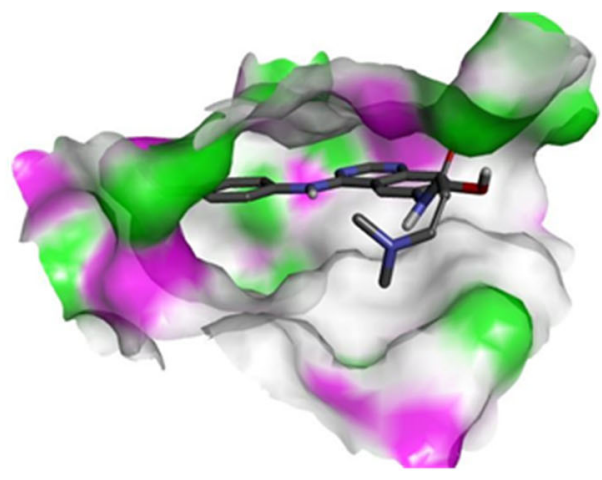

(b1)

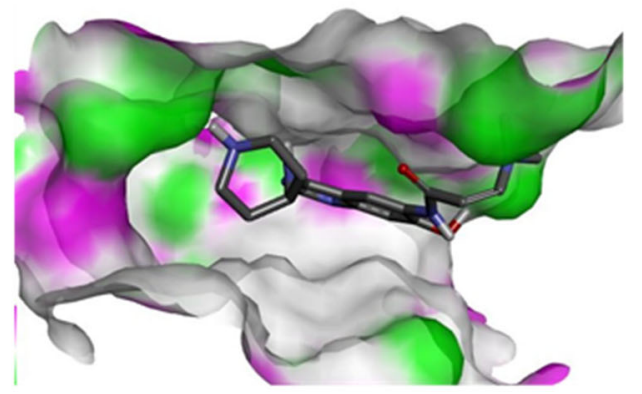

(c1)

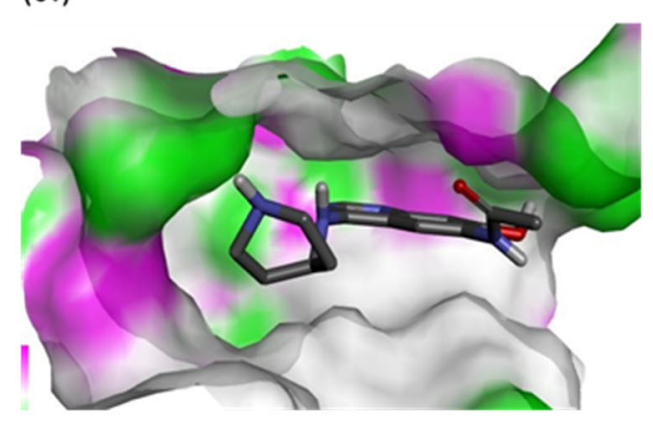

All new compounds also display hydrophobic interactions that act as anchors in maintaining the position of inhibitors in the EGFR protein pocket. This docking result was then evaluated through molecular dynamics simulation to identify the interaction stability of new compounds in EGFR protein. Besides proteinligand interactions, a comparison of docking scores could
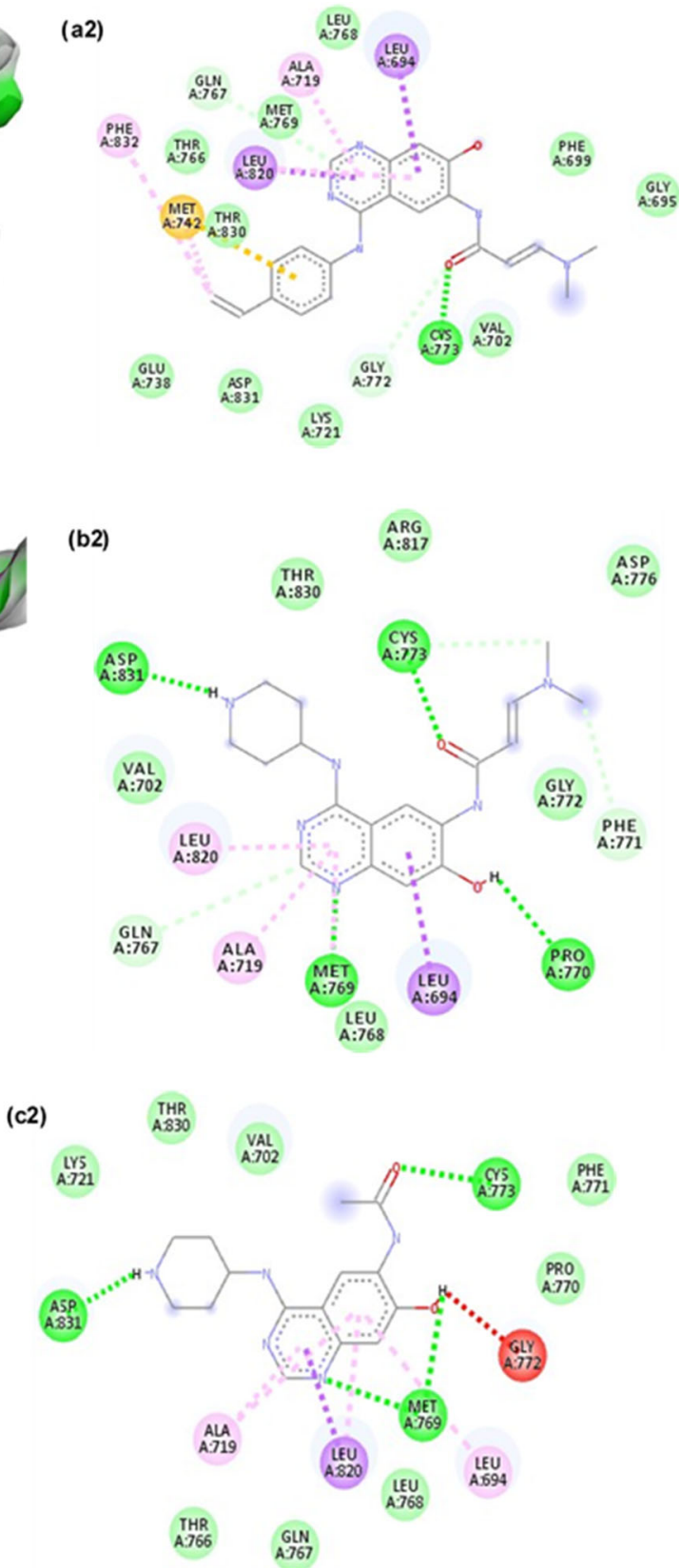

Fig 3. 3D and $2 \mathrm{D}$ interaction of (a1) and (a2) A1-EGFR, (b1) and (b2) B1-EGFR, and (c1) and (c2) C1-EGFR complexes. Type of interactions: — van der Waals, salt bridge, conventional hydrogen bond, carbon hydrogen bond, — pi-sigma, _ pi-alkyl, — pi-sulfur, and —unfavorable donor-donor 
be used as preliminary indications of whether the design compound better or not. Table 1 shows the docking score of each ligand, and it appears that the new design compound has a lower docking score indicating it has the potential to be a better inhibitor.

\section{Molecular Dynamics Simulation}

\section{Hydrogen bond stability}

Molecular dynamics simulation had been carried out through $13 \mathrm{~ns}$ simulation time for all new compounds against EGFR protein. Fig. 4 showed the hydrogen bond distance plot of compound Al with some residues of EGFR. Interaction ligand A1 and EGFR before and after simulation showed similar interaction despite different residual numbers due to the renumbering system by the Amber program.

Two hydrogen bond interactions are in Met98 and Cys102 residues. The stable interactions resulting from compound $\mathrm{A} 1(\mathrm{~N})$ and Met $98(\mathrm{H})$, which could be seen through the constant distance during simulation time, were about 2-3 $\AA$. An additional hydrogen bond is also presented from compound $\mathrm{A} 1(\mathrm{O})$ against Cys102(H) residue, and this belongs to weak interaction due to the distance during simulation time was about 4-5 A. Fig. 5 showed the snapshot of complex A1 and residue of EGFR protein.

Hydrogen bond stability of compound B1 against EGFR showed a different result between docking results and molecular dynamics simulation. Docking result showed that ligand B1 interacted with Met769, Cys773, and Asp831. However, after simulation, B1 interacted with Met98 (supposed to Met769), Lys50, and Thr95. Fig. 6 presented the graph of hydrogen bond distance of B1 compound against amino acid residues Met98, Lys50, and Thr95. Stable interaction was obtained from B1(N) with
Met98(H) residue, while the other two interactions tend to be unstable. Interaction B1(N3) with Lys50(HZ3) had a high fluctuating distance of about 2 until $6 \AA$. Furthermore, B1(N1) and Thr95(HG1) interaction had

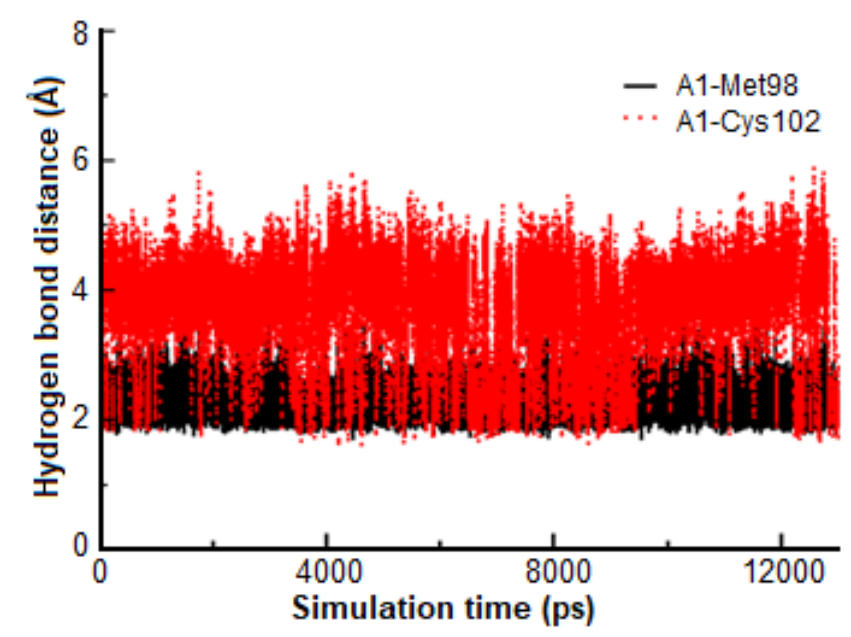

Fig 4. Hydrogen bond distance plot of compound A1 with EGFR protein

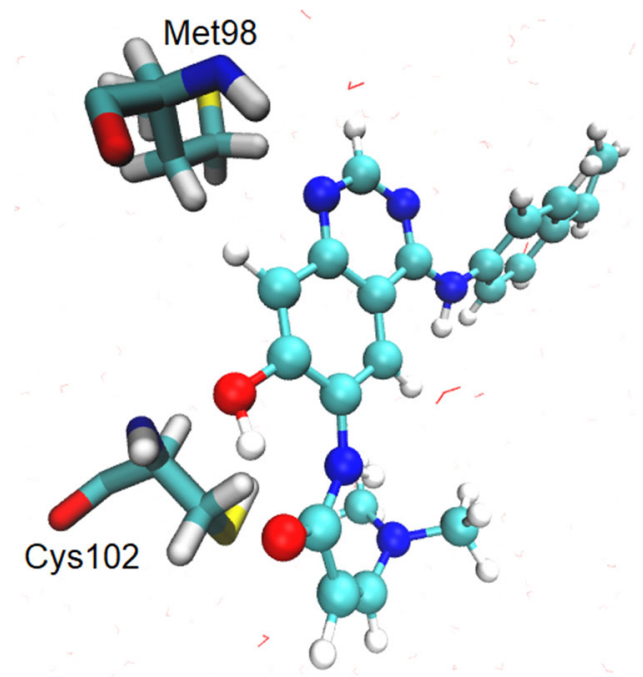

Fig 5. Snapshot of complex A1 and residue of EGFR protein in water

Table 1. Docking score value and hydrogen bond interaction of each ligand

\begin{tabular}{ccl}
\hline Compound & Docking Score $(\mathrm{kJ} / \mathrm{mol})$ & Hydrogen bond interaction residue \\
\hline Erlotinib & -20.2506 & Met769 \\
Afatinib & -25.0622 & Met793; Cys797; Leu718; Asn842 \\
WZ4002 & -22.2589 & Met793 \\
A1 & -25.5642 & Met769; Cys773 \\
B1 & -29.3298 & Met769; Cys773; Asp831 \\
C1 & -29.2043 & Met769; Met769; Cys773; Asp831 \\
\hline
\end{tabular}




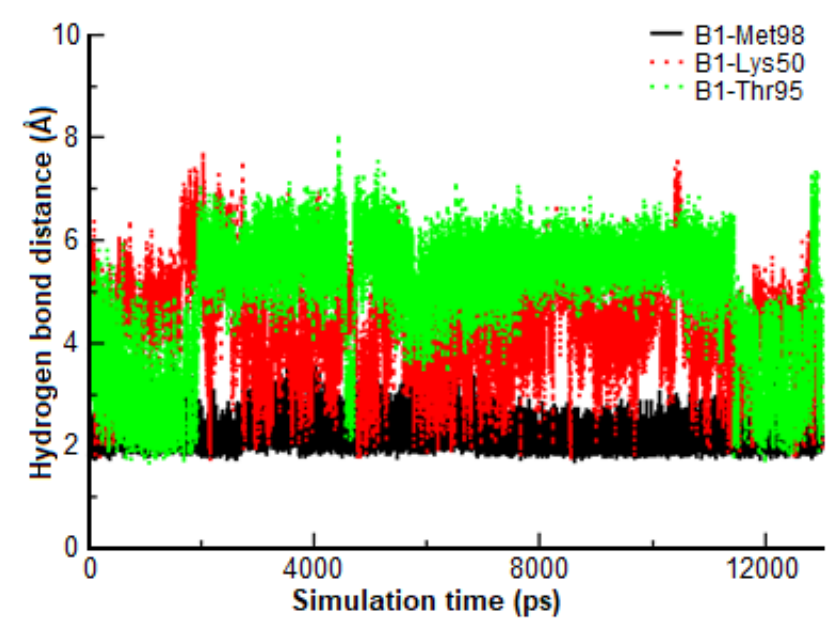

Fig 6. Hydrogen bond distance plot of compound B1 with EGFR protein

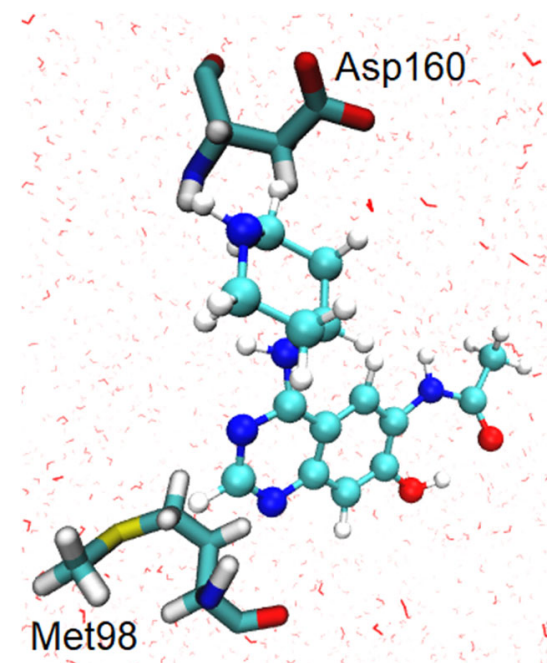

Fig 7. Snapshot of complex B1 and residue of EGFR protein in water

a fluctuating bond distance as well, about 2 until $7 \AA$ Å. Fig. 7 showed the snapshot of compound $\mathrm{B} 1$ and the residue of EGFR protein.

There were four hydrogen bond interactions during simulation time between compound $\mathrm{C} 1$ against EGFR protein. One of the residues shown before simulation but disappeared after simulation time, that is Asp831 replaced by Glu67. Fig. 8 depicted the distance graph of each interaction. Hydrogen bond interaction of $\mathrm{C} 1(\mathrm{~N})$ with Met98(H) residue was formed at about $2 \AA$ during the simulation time. Interaction $\mathrm{C} 1(\mathrm{O} 1)$ and $\mathrm{Cys} 102(\mathrm{H})$ appeared at about 4 until $8 \AA$, while interaction $\mathrm{C} 1(\mathrm{H} 1)$ and Glu67(OE2) had a more stable distance about 2 until
$4 \AA$ A. The other interaction, C1(N1) and Lys50(HZ3) showed a weak hydrogen bond interaction because the distance appeared at 2 until $6 \AA$. A snapshot of interaction compound $\mathrm{C} 1$ and residue of EGFR protein was performed in Fig. 9.

\section{Stability analysis}

All the design compounds were then evaluated for stability by RMSD and RMSF analysis for each compound compared with erlotinib as a standard and EGFR protein without any binding ligands.

This analysis was used to identify whether the three design compounds can improve the stability of EGFR protein compared to erlotinib and EGFR without the presence of ligands. Compounds that potential as EGFR

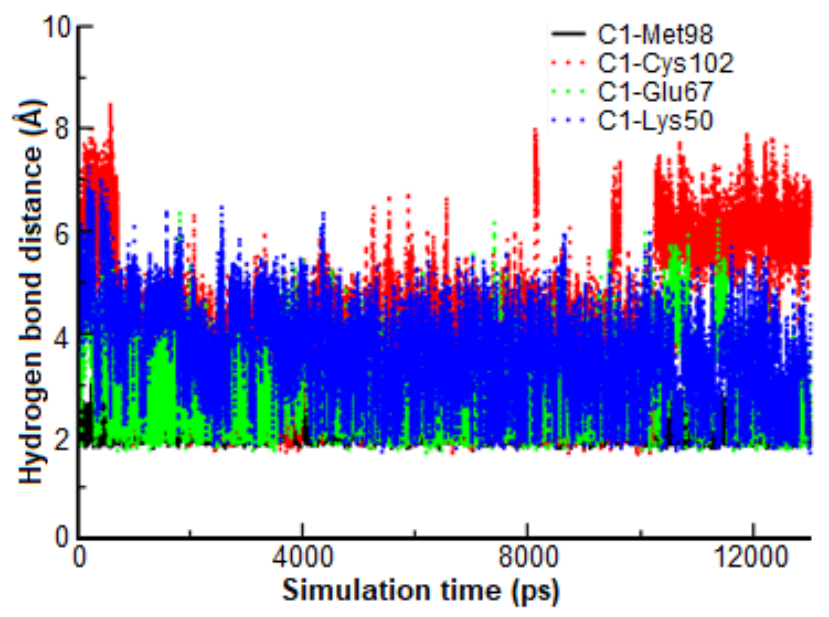

Fig 8. Hydrogen bond distance plot of compound $\mathrm{C} 1$ with EGFR protein

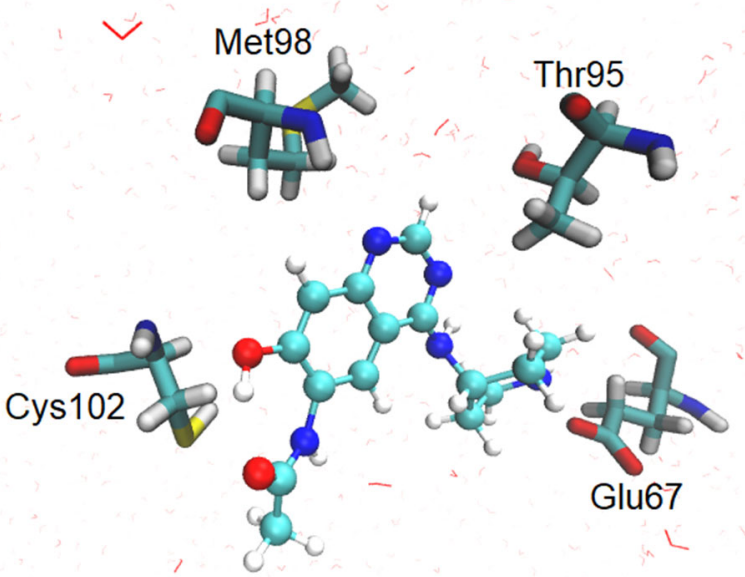

Fig 9. Snapshot of $\mathrm{C} 1$ complex and residue of EGFR protein in water 
inhibitors are certainly expected to increase the stability of EGFR compared to erlotinib compounds that had been resistant to EGFR.

Fig. 10 represents an RMSD analysis for each complex ligand against EGFR protein. Compounds B1 and $\mathrm{C} 1$ showed the lowest RMSD compared to other compounds during simulation time. Both compounds showed increased stability toward the EGFR protein, which can be caused by the number of hydrogen bonds produced during the simulation time, which is greater than the hydrogen bond of compound A1. This result is also supported by RMSF analysis, where the lowest fluctuations based on residual numbers occurred in the complex B1 against EGFR protein (see Fig. 11).

\section{MM-GBSA Binding Energy Calculation}

Binding energy calculation of all complexes was exhibited by the MMGBSA method [34] (Eq. (1)). Table 2 showed the calculation result that ligand $\mathrm{A} 1$ and $\mathrm{C} 1$ have lower binding energy than erlotinib. Furthermore,

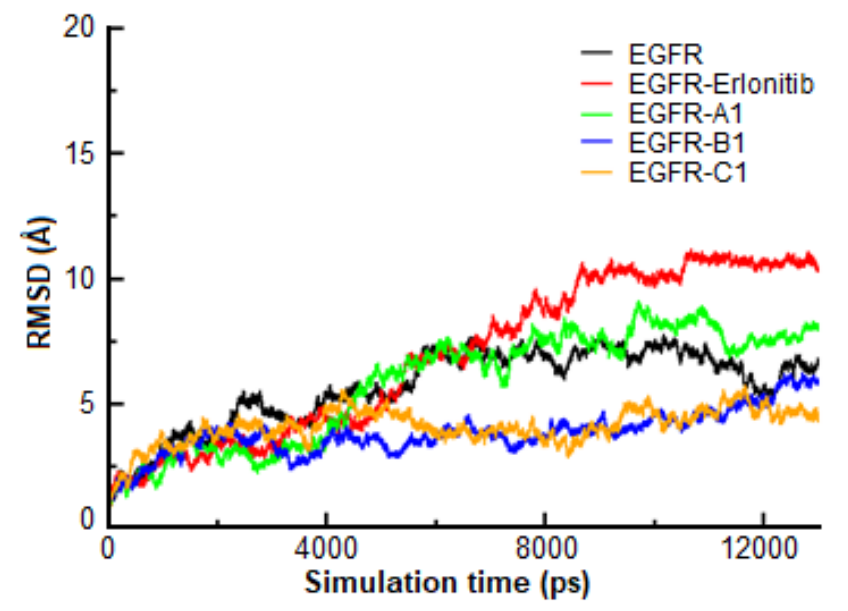

Fig 10. RMSD graph of EGFR and complex EGFR-ligand compound A1 had the lowest binding energy indicated that compound $\mathrm{Al}$ is the potential to be an EGFR inhibitor.

$$
\Delta \mathrm{G}_{\text {binding }}=\mathrm{G}_{\text {complex }}(\mathrm{i})-\mathrm{G}_{\text {protein }}(\mathrm{i})-\mathrm{G}_{\text {inhibitor }}(\mathrm{i})_{\mathrm{i}}
$$

\section{- CONCLUSION}

The combination of docking and molecular dynamics simulation had been carried out to design new quinazoline derivatives compounds. Molecular docking was successful in designing new potential compounds using the pharmacophore model of lead compounds. There were three new potential compounds produced (A1; B1; and C1), and their interactions were evaluated via molecular dynamics simulation. The result of the simulation showed a more stable interaction between the $\mathrm{A} 1$ and $\mathrm{C} 1$ compounds. Furthermore, compound $\mathrm{A} 1$ exhibits the lowest binding energy result; about $-164.4330 \mathrm{~kJ} / \mathrm{mol}$ indicated that $\mathrm{A} 1$ is a potential compound as an EGFR inhibitor.

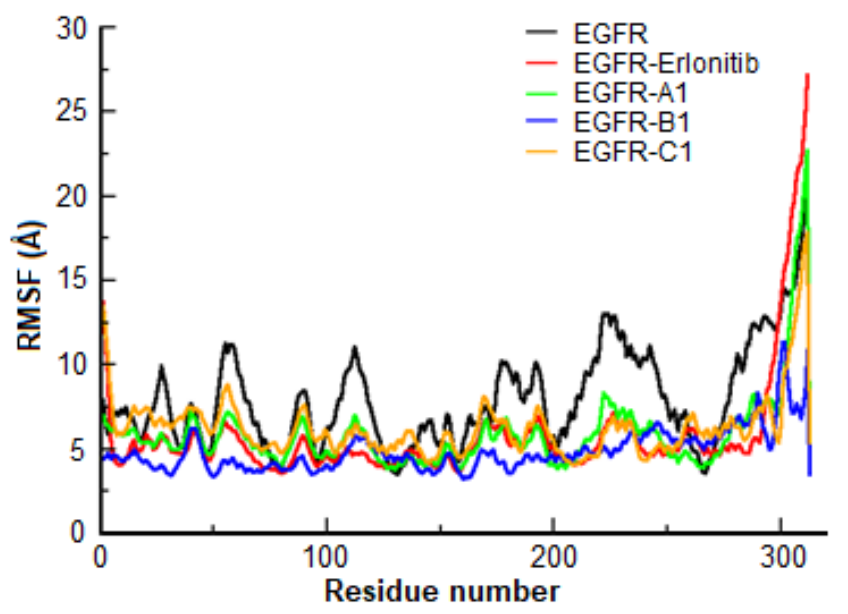

Fig 11. RMSF graph of EGFR and complex EGFR-ligand

Table 2. MMGBSA energy calculation result $(\mathrm{kJ} / \mathrm{mol})$

\begin{tabular}{lcccc}
\hline \multicolumn{1}{c}{ Energy } & $\mathrm{A} 1$ & $\mathrm{~B} 1$ & $\mathrm{C} 1$ & Erlotinib \\
\hline Van der Waals & -208.7230 & -171.5590 & -189.4682 & -209.7849 \\
EEL & -102.9808 & -140.8163 & -89.6832 & -97.6156 \\
EGB & 174.6008 & 189.5344 & 139.2376 & 171.8373 \\
ESURF & -27.3190 & -22.8948 & -23.5304 & -25.4303 \\
\hline$\Delta \mathrm{G}_{\text {gas }}$ & -311.7038 & -312.3753 & -279.1514 & -307.4005 \\
$\Delta \mathrm{G}_{\text {solv }}$ & 147.2818 & 166.6396 & 115.7072 & 146.4070 \\
\hline$\Delta \mathrm{G}_{\text {binding }}$ & -164.4220 & -145.7357 & -163.4442 & -160.9935 \\
\hline
\end{tabular}




\section{- ACKNOWLEDGMENTS}

H. Rasyid acknowledges a Ph.D. scholarship issued by the Ministry of Research, Technology, and Higher Education of the Republic of Indonesia (1511/E4.4/2015). Authors also acknowledge the Research Directorate of Universitas Gadjah Mada for research funding under the scheme of Rekognisi Tugas Akhir (RTA).

\section{- REFERENCES}

[1] Herbst, R.S., 2004, Review of epidermal growth factor receptor biology, Int. J. Radiat. Oncol. Biol. Phys., 59 (2), S21-S26.

[2] Vallbohmer, D., and Lenz, H.J., 2005, Epidermal growth factor receptor as a target for chemotherapy, Clin. Colorectal Cancer, 5 (Suppl. 1), S19-27.

[3] Baselga, J., 2002, Why the epidermal growth factor receptor? The rationale for cancer therapy, Oncologist, 7 (Suppl. 4), 2-8.

[4] Singh, M., and Jadhav, H.R., 2018, Targeting nonsmall cell lung cancer with small-molecule EGFR tyrosine kinase inhibitors, Drug Discovery Today, 23 (3), 745-753.

[5] Ismail, R.S.M., Ismail, N.S.M., Abuserii, S., and Abou El Ella, D.A., 2016, Recent advances in 4aminoquinazoline based scaffold derivatives targeting EGFR kinases as anticancer agents, Future J. Pharm. Sci., 2 (1), 9-19.

[6] Yu, H., Li, Y., Ge, Y., Song, Z., Wang, C., Huang, S., Jin, Y., Han, X., Zhen, Y., Liu, K., Zhou, Y., and Ma, $\mathrm{X}$., 2016, Novel 4-anilinoquinazoline derivatives featuring an 1-adamantyl moiety as potent EGFR inhibitors with enhanced activity against NSCLC cell lines, Eur. J. Med. Chem., 110, 195-203.

[7] Chen, Y.M., Luo, Y.H., Wu, C., Lee, Y.C., Perng, R.P., and Whang-Peng, J., 2015, Erlotinib or chemotherapy in second-lne or later treatment of tumor EGFR wild-type pulmonary adenocarcinoma patients, J. Cancer Res. Pract., 2 (1), 3-11.

[8] Teraishi, F., Kagawa, S., Watanabe, T., Tango, Y., Kawashima, T., Umeoka, T., Nisizaki, M., Tanaka, N., and Fujiwara, T., 2005, ZD1839 (Gefitinib, 'Iressa'), an epidermal growth factor receptortyrosine kinase inhibitor, enhances the anti-cancer effects of TRAIL in human esophageal squamous cell carcinoma, FEBS Lett., 579 (19), 4069-4075.

[9] Tu, Y., Ouyang, Y., Xu, S., Zhu, Y., Li, G., Sun, C., Zheng, P., and Zhu, W., 2016, Design, synthesis, and docking studies of afatinib analogs bearing cinnamamide moiety as potent EGFR inhibitors, Bioorg. Med. Chem., 24 (7), 1495-1503.

[10] Cheng, H., Nair, S.K., and Murray, B.W., 2016, Recent progress on third generation covalent EGFR inhibitors, Bioorg. Med. Chem. Lett., 26 (8), 18611868.

[11] Kobayashi, S., Boggon, T.J., Dayaram, T., Jänne, P.A., Kocher, O., Meyerson, M., Johnson, B.E., Eck, M.J., Tenen, D.G., and Halmos, B., 2005, EGFR mutation and resistance of non-small-cell lung cancer to gefitinib, N. Engl. J. Med., 352 (8), 786-792.

[12] Li, D., Ambrogio, L., Shimamura, T., Kubo, S., Takahashi, M., Chirieac, L.R., Padera, R.F., Shapiro, G.I., Baum, A., Himmelsbach, F., Rettig, W.J., Meyerson, M., Solca, F., Greulich, H., and Wong, K.K., 2008, BIBW2992, an irreversible EGFR/HER2 inhibitor highly effective in preclinical lung cancer models, Oncogene, 27 (34), 4702-4711.

[13] Wang, S., Song, Y., and Liu, D., 2017, EAI045: The fourth-generation EGFR inhibitor overcoming T790M and C797S resistance, Cancer Lett., 385, 5154.

[14] Huey, R., Morris, G.M., Olson, A.J., and Goodsell, D.S., 2007, A semiempirical free energy force field with charge-based desolvation, J. Comput. Chem., 28 (6), 1145-1152.

[15] Traxler, P., Green, J., Mett, H., Séquin, U., and Furet, P., 1999, Use of a pharmacophore model for the design of EGFR tyrosine kinase inhibitors: Isoflavones and 3-phenyl-4(1H)-quinolones, $J$. Med. Chem., 42, 1018-1026.

[16] Istyastono, E.P., 2017, Binary quantitative structure-activity relationship analysis to increase the predictive ability of structure-based virtual screening campaigns targeting cyclooxygenase-2, Indones. J. Chem., 17 (2), 322-329.

[17] Rasyid, H., Purwono, B., and Armunanto, R., 2018, Quantitative structure activity relationship (QSAR) 
based on electronic descriptors and docking studies of quinazoline derivatives for anticancer activity, Orient. J. Chem., 34 (5), 2361-2369.

[18] Pranowo, H.D., Tahir, I., and Widiatmoko, A., 2007, Quantitative relationship of electronic structure and inhibition activity of curcumin analogs on ethoxyresorufin o-dealkylation (EROD) reaction, Indones. J. Chem., 7 (1), 78-82.

[19] Rasyid, H., Purwono, B., Hofer, T.S., and Pranowo, H.D., 2019, Hydrogen bond stability of quinazoline derivatives compounds in complex against EGFR using molecular dynamics simulation, Indones. J. Chem., 19 (2), 461-469.

[20] Pitaloka, D.A.E., Damayanti, S., Artarini, A.A., and Sukandar, E.Y., 2019, Molecular docking, dynamics simulation, and scanning electron microscopy (SEM) examination of clinically isolated Mycobacterium tuberculosis by ursolic acid: A pentacyclic triterpenes, Indones. J. Chem., 19 (2), 328-336.

[21] Dwiastuti, R., Radifar, M., Marchaban, M., Noegrohati, S., and Istyastono, E.P., 2016, Molecular dynamics simulations and empirical observations on soy lecithin liposome preparation, Indones. J. Chem., 16 (2), 222-228.

[22] Arba, M., Sufriadin, M., and Tjahjono, D.H., 2020, Identification of phosphatidylinositol 3-kinase $\delta$ (PI3K $\delta)$ Inhibitor: pharmacophore-based virtual screening and molecular dynamics simulation, Indones. J. Chem., 20 (5), 1070-1079.

[23] Morris, G., and Huey, R., 2009, AutoDock4 and AutoDockTools4: Automated docking with selective receptor flexibility, J. Comput. Chem., 30 (16), 27852791.

[24] Frisch, M.J., Trucks, G.W., Schlegel, H.B., Scuseria, G.E., Robb, M.A., Cheeseman, J.R., Scalmani, G., Barone, V., Petersson, G. A., Nakatsuji, H., Li, X., Caricato, M., Marenich, A.V., Bloino, J., Janesko, B.G., Gomperts, R., Mennucci, B., Hratchian, H.P., Ortiz, J.V., Izmaylov, A.F., Sonnenberg, J.L., Williams-Young, D., Ding, F., Lipparini, F., Egidi, F., Goings, J., Peng, B., Petrone, A., Henderson, T., Ranasinghe, D., Zakrzewski, V.G., Gao, J., Rega, N., Zheng, G., Liang, W., Hada, M., Ehara, M., Toyota,
K., Fukuda, R., Hasegawa, J., Ishida, M., Nakajima, T., Honda, Y., Kitao, O., Nakai, H., Vreven, T., Throssell, K., Montgomery, J.A., Jr., Peralta, J.E., Ogliaro, F., Bearpark, M.J., Heyd, J.J., Brothers, E.N., Kudin, K.N., Staroverov, V.N., Keith, T.A., Kobayashi, R., Normand, J., Raghavachari, K., Rendell, A.P., Burant, J.C., Iyengar, S.S., Tomasi, J., Cossi, M., Millam, J.M., Klene, M., Adamo, C., Cammi, R., Ochterski, J.W., Martin, R.L., Morokuma, K., Farkas, O., Foresman, J.B., and Fox, D.J., 2016, Gaussian 16, Revision C.02, Gaussian, Inc., Wallingford CT.

[25] Dassault Systèmes BIOVIA, 2019, Discovery Studio Visualizer v.20.1.0.19295, Dassault Systèmes, San Diego, USA.

[26] Pettersen, E.F., Goddard, T.D., Huang, C.C., Couch, G.S., Greenblatt, D.M., Meng, E.C., and Ferrin, T.E., 2004, UCSF Chimera-a visualization system for exploratory research and analysis, $J$ Comput Chem., 25 (13), 1605-1612.

[27] Case, D.A., Betz, R.M., Botello-Smith, W., Cerutti, D.S., Cheatham, T.E., Darden, T.A., Duke, R.E., Giese, T.J., Gohlke, H., Goetz, A.W., Homeyer, N., Izadi, S., Janowski, P., Kaus, J., Kovalenko, A., Lee, T.S., LeGrand, S., Li, P., Lin, C., Luchko, T., Luo, R., Madej, B., Mermelstein, D., Merz, K.M., Monard, G., Nguyen, H., Nguyen, H.T., Omelyan, I., Onufriev, A., Roe, D.R., Roitberg, A., Sagui, C., Simmerling, C.L., Swails, J., Walker, R.C., Wang, J., Wolf, R.M., Wu, X., Xiao, L., York, D.M., and Kollman, P.A., 2016, AMBER 2016, University of California, San Francisco.

[28] Humprey, W., Dalke, A., and Schulten, K., 1996, VMD: Visual molecular dynamics, J. Mol. Graphics, 14, 33-38.

[29] Wang, J., Wolf, R.M., Caldwell, J.W., Kollman, P.A., and Case, D.A., 2004, Development and testing of a general AMBER force field, J. Comput. Chem., 25 (9), 1157-1174.

[30] Jorgensen, W.L., Chandrasekhar, J., Madura, J.D., Impey, R.W., and Klein, M.L., 1983, Comparison of simple potential functions for simulating liquid water, J. Chem. Phys., 79 (2), 926-935. 
[31] Mustafa, M., Mirza, A., and Kannan, N., 2011, Conformational regulation of the EGFR kinase core by the juxtamembrane and C-terminal tail: A molecular dynamics study, Proteins Struct. Funct. Bioinf., 79 (1), 99-114.

[32] Liu, B., Bernard, B., and Wu, J.H., 2006, Impact of EGFR point mutations on the sensitivity to gefitinib: Insights from comparative structural analyses and molecular dynamics simulations, Proteins, 65 (2), 346, 331-346.

[33] Darden, T., York, D., and Pedersen, L., 1993, Particle mesh Ewald: An N log (N) method for Ewald sums in large systems, J. Chem. Phys., 98 (12), 10089-10092.

[34] Miller, B.R., McGee, T.D., Swails, J.M., Homeyer, N., Gohlke, H., and Roitberg, A.E., 2012, MMPBSA.py: An efficient program for end-state free energy calculations, J. Chem. Theory Comput., 8 (9), 33143321.

[35] Patel, H., Pawara, R., Ansari, A., and Surana, S., 2017, Recent updates on third generation EGFR inhibitors and emergence of fourth generation EGFR inhibitors to combat C797S resistance, Eur. J. Med. Chem., 142, 32-47.

[36] Stamos, J., Sliwkowski, M.X., and Eigenbrot, C., 2002, Structure of the epidermal growth factor receptor kinase domain alone and in complex with a 4-anilinoquinazoline inhibitor, J. Biol. Chem., 277 (48), 46265-46272.

[37] Hou, T., Zhu, L., Chen, L., and Xu, X., 2003, Mapping the binding site of a large set of quinazoline type EGF-R inhibitors using molecular field analyses and molecular docking studies, J. Chem. Inf. Comput. Sci., 43 (1), 273-283.

[38] Rabindran, S.K., Discafani, C.M., Rosfjord, E.C., Baxter, M., Floyd, M.B., Golas, J., Hallett, W.A., Johnson, B.D., Nilakantan, R., Overbeek, E., Reich, M.F., Shen, R., Shi, X., Tsou, H.R., Wang, Y.F., and Wissner, A., 2004, Antitumor activity of HKI-272, an orally active, irreversible inhibitor of the HER-2 tyrosine kinase, Cancer Res., 64 (11), 3958-3965.

[39] Eskens, F.A.L.M., Mom, C.H., Planting, A.S.T., Gietema, J.A., Amelsberg, A., Huisman, H., van Doorn, L., Burger, H., Stopfer, P., Verweij, J., and de Vries, E.G.E., 2008, A phase I dose escalation study of BIBW 2992, an irreversible dual inhibitor of epidermal growth factor receptor 1 (EGFR) and 2 (HER2) tyrosine kinase in a 2-week on, 2-week off schedule in patients with advanced solid tumours, Br. J. Cancer, 98 (1), 80-85. 